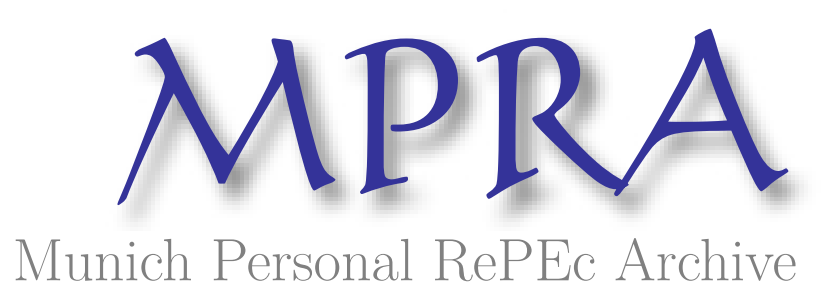

\title{
An Alternative to the BDS Test: Integration Across the Correlation Integral
}

Kocenda, Evzen

September 1996

Online at https://mpra.ub.uni-muenchen.de/70510/

MPRA Paper No. 70510, posted 07 Apr 2016 18:35 UTC 


\title{
A Test for iid Residuals \\ Based on Integrating Over the Correlation Integral
}

\author{
Evžen Kočenda \\ CERGE-EI, Prague, Czech Republic
}

\begin{abstract}
:
This paper presents a new method of testing for iid. The test is suggested as an alternative to the nonparametric BDS test, which requires a proximity parameter $\varepsilon$ and an embedding dimension $m$ to be chosen arbitrarily. A limited statistical theory exists to determine the right choice of these parameters. The presented method aims to eliminate such indecisiveness by integration over the correlation integral. The Monte Carlo simulation is used to tabulate critical values of the new statistic. In a comparative analysis the presented test is able to find nonlinear dependencies in cases where the BDS test does not find them. The test becomes more critical to the question whether the data is true white noise.
\end{abstract}

\begin{abstract}
Abstrakt:
V článku je popisována nová metoda testovaní nezávislého a identického rozdělení (iid). Test je navržen jako alternativa $k$ neparametrickému testu BDS, který vyžaduje, aby parametr proximity $\varepsilon$ a prostorová dimenze $m$ byly zvoleny arbitrálně. $K$ dispozici je pouze nejednoznačná statistická teorie jak nejlépe vybrat tyto dva paramery. Navržená metoda nabízí odstranění této nerozhodnosti pomocí integrace přes korelační integrál. Kritické hodnoty nové statistiky jsou tabulovány pomocí Monte Carlo simulace. Komparativní analýza dokazuje, že navrhovaý test je schopen najít nelineární závislosti v př́ípadech, kde je test BDS již nenachází. Nový test se tak stává př́ísnějším k otázce zda jsou data skutečně pouhý bílý šum.
\end{abstract}

Keywords: chaos, nonlinear dynamics, correlation integral, Monte Carlo, exchange rates, ARCH

JEL Classification: C14, C15, F31

I would like to thank D. Dechert whose help with this paper was substantial.

I would also like to thank B. LeBaron and C. Lenz for the data sets and helpful comments, J. Perez for providing me with the data set, and D. Papell for his helpful comments. The usual disclaimer applies. 


\section{Introduction}

Applications of deterministic nonlinear dynamics and chaos theory to the analysis of stochastic economic time series are widely used in contemporary macroeconomics and finance. A broad pioneering volume on the complexity of the economy edited by Anderson, Arrow and Pines (1988) includes a paper by Brock (1988) that is closely related to the previously mentioned topic. A recent result in this trend is a non parametric method of testing for nonlinear patterns in time series devised by Brock, Dechert and Scheinkman (1987) and further developed in Brock, Dechert, Scheinkman and LeBaron (1996). The method is known as the BDS test. Its null hypothesis is that data in a time series is independently and identically distributed (iid). The test is unique in its ability to detect nonlinearities while not being affected by linear dependencies in the data.

This paper suggests an alternative testing method that aims to eliminate some shortcomings associated with the BDS test. Both methods are based on the theoretical concept of the correlation integral described by Grassberger and Procaccia (1983). In order to conduct the BDS test, certain parameters of it must be chosen arbitrarily, ex ante. A limited statistical theory exists on how to determine these parameters. An erroneous choice of them is thus likely to occur. The proposed alternative is constructed in a way that, to a large extent, eliminates necessity of such an arbitrary choice. Empirical comparison shows that the alternative test is more critical as it finds remains of nonlinearities where the BDS test does not.

The paper is organized in the following manner. Section 2 provides a brief theoretical background on why the alternative test is suggested. Section 3 describes construction of the new testing method. Further, a Monte Carlo technique is employed to 
tabulate critical values of the newly designed statistic for different significance levels to enable hypothesis testing. Section 4 presents power tests and puts forth an empirical comparison. Several studies are replicated and the original results of the BDS test are compared with those of the suggested alternative. Section 5 briefly concludes.

\section{Theoretical Background}

Chaotic systems of low complexity can generate seemingly random numbers that may successfully mimic white noise and do not reveal their true nature. Under presumed randomness, a nonlinear pattern can hide without being detected. Exchange rates, stock market returns and other macroeconomic variables of generally high frequency are likely to originate from low complexity chaos. Detection of nonlinear hidden patterns in such time series provides important information about their behavior and improves the forecasting ability over short time periods. However, a potent testing procedure is needed at first.

It is widely acknowledged that the best known technique for the analysis of chaotic systems is the correlation dimension. This is because of an easy computation and the availability of a sampling theory. The test developed by Brock, Dechert, and Scheinkman (1987), further referred to as the BDS test, is based on the mentioned technique and was designed to detect hidden patterns in stochastic time series. It was recently explicated to the fullest extent in Brock, Dechert, Scheinkman, and LeBaron (1996) which can serve as a detailed reference. The method uses the concept of the correlation integral, employed by Grassberger and Procaccia (1983), to distinguish between chaotic deterministic systems and stochastic systems. In order to keep the paper 
at a reasonable length, the reader should refer to the references cited in this section for more profound theoretical background.

The BDS statistic is defined as

$$
\operatorname{BDS}_{\mathrm{m}, \mathrm{T}}(\varepsilon)=\mathrm{T}^{\frac{1}{2}}\left[\mathrm{C}_{\mathrm{m}, \mathrm{T}}(\varepsilon)-\mathrm{C}_{1, \mathrm{~T}}(\varepsilon)^{\mathrm{m}}\right] / \sigma_{\mathrm{m}, \mathrm{T}}(\varepsilon)
$$

where $\mathrm{C}_{\mathrm{m}, \mathrm{T}}(\varepsilon)$ is a value of a correlation integral or a number of clustered pairs lying within a particular tolerance distance $\varepsilon$ at a spatial dimension $\mathrm{m}$, and $\sigma_{\mathrm{m}, \mathrm{T}}(\varepsilon)$ is a standard deviation of the statistic that varies with dimension $\mathrm{m}$. The proximity parameter $\varepsilon$ is chosen arbitrarily and is chiefly enumerated as a ratio of the sample's standard deviation.

The BDS test is a nonparametric test of the null hypothesis that the data is independently and identically distributed (iid) against an unspecified alternative. The test enables one to test for nonlinear dependence because it is not affected by linear dependencies in the data. The employed procedure has power against both deterministic and stochastic systems. The ability of this test to deal with stochastic time series makes it strongly appealing for its application in modern macroeconomics and financial economics.

The main feature of this test is its ability to detect nonlinear patterns in the data, an obvious improvement over linearly oriented tests. Further detailed explanation and application of the BDS test can be found in the original paper as well as in representative studies by Brock and Dechert (1988), Hsieh (1989), Hsieh (1991), Brock, Hsieh and LeBaron (1993), and Brock, Dechert, Scheinkman and LeBaron (1996).

By using pairs of histories that cluster together within a specific distance $\varepsilon$ too often, the BDS test is able to reveal hidden patterns which should not occur in a truly 
randomly distributed data. A "pattern" is defined as a repetitive occurrence of two histories that lie within a certain distance $\varepsilon$ of each other for different spatial (embedding) dimensions $m$.

While the BDS statistic is easy to compute, only a limited statistical theory exists on how to determine the optimal proximity parameter. If $\varepsilon$ is too large, then all the points are closer than $\varepsilon$, giving a constant value of correlation integral for every $m$. However, if $\varepsilon$ is too small, then correlation integral captures too few points and yields inaccurate estimates. One approach to taking $\varepsilon$ to zero with increasing sample size is described in Dechert (1994). Another is to chose $\varepsilon$ that maximizes power against some particular alternative. Brock, Dechert, Scheinkman and LeBaron (1996) showed that for any $\varepsilon$ for which $\mathrm{K}(\varepsilon)-\mathrm{C}(\varepsilon)^{2}>0$, it is the case that the BDS statistic is asymptotically normal. ${ }^{1}$ In principle, it means that the results are independent of the choice of $\varepsilon$. However, in practice, the rate of convergence may depend on the value of $\varepsilon$. Thus, which value of $\varepsilon$ gives us the "best" test is a legitimate question to ask. Usually $\varepsilon$ is enumerated as a fraction of the standard deviation of the sample.

Another parameter that appears in the BDS statistic is $\mathrm{m}$, representing the embedding or spatial dimension. The choice of the parameter depends on which lag the investigator wishes to test for dependence. DeLima (1992) developed a class of statistical tests of iid which "integrate" over $\mathrm{m}$ and $\varepsilon$ but still preserve the invariance property. Another approach for the choice of $\mathrm{m}$ can be characterized as: higher the order of underlying pattern in a time series, the larger magnitudes of $\mathrm{m}$ should be included in the

\footnotetext{
${ }^{1}$ See Brock, Dechert, Scheinkman and LeBaron (1996) for details.
} 
test. However, the order of pattern is likely to be unknown. The main problem is that that as we increase $\mathrm{m}$, then fewer and fewer non-overlapping $\mathrm{m}$-histories will be available. It means that for samples of moderate size only a low-dimensional chaos will be characterized.

Heretofore, the BDS statistic has been calculated only for a few values of the proximity parameter (tolerance distance) which appears in the statistic and must be chosen arbitrarily prior the test is conducted. This was brought about, in part, by the Monte Carlo studies of Hsieh and LeBaron (1988) who tested the asymptotic normally of the statistic for only three values of the parameter. The fact that the BDS statistic is calculated for only a few values of proximity parameter is not in the spirit of the Grassberger-Proccacia correlation integral (on which the statistic is based) which is typically calculated over a broad range of the proximity parameter, and in particular for a number of small values of the parameter.

It is the aim of this paper to propose an alternative testing method that eliminates the above mentioned shortcomings. Minimizing indecisiveness of what the proper distance $\varepsilon$ and spatial dimension $m$ should be seems to represent the avenue to go.

\section{An alternative test}

Let $\left\{x_{t}\right\}$ be a scalar time series of length T. Form m-dimensional vectors, called m-histories, $\mathrm{x}_{\mathrm{t}}^{\mathrm{m}}=\left(\mathrm{x}_{\mathrm{t}}, \mathrm{x}_{\mathrm{t}+1}, \ldots, \mathrm{x}_{\mathrm{t}+\mathrm{m}-1}\right)$. Such $\mathrm{m}$-dimensional vectors are used to calculate correlation integral at embedding dimension $m$ which is given by

$$
\mathrm{C}_{\mathrm{m}, \mathrm{T}}(\varepsilon)=\sum_{\mathrm{t}=1}^{\mathrm{T}_{\mathrm{m}-1}} \sum_{\mathrm{s}=\mathrm{t}+1}^{\mathrm{T}_{\mathrm{m}}} \mathrm{I}_{\varepsilon}\left(\mathrm{x}_{\mathrm{t}}^{\mathrm{m}}, \mathrm{x}_{\mathrm{s}}^{\mathrm{m}}\right) \cdot\left(2 / \mathrm{T}_{\mathrm{m}}\left(\mathrm{T}_{\mathrm{m}}-1\right)\right)
$$


where $T_{m}=T-m+1$, and $I_{\varepsilon}\left(x_{t}^{m}, x_{s}^{m}\right)$ is an indicator function of event

$$
\left\|\mathrm{x}_{\mathrm{t}}^{\mathrm{m}}-\mathrm{x}_{\mathrm{s}}^{\mathrm{m}}\right\|=\sup _{\mathrm{i}=0, \ldots, \mathrm{m}-1}\left|\mathrm{x}_{\mathrm{t}+\mathrm{i}}-\mathrm{x}_{\mathrm{s}+1}\right|<\varepsilon
$$

Thus the correlation integral measures fraction of pairs that lie within the tolerance distance $\varepsilon$ for particular spatial dimension m. Grassberger and Procaccia (1983) used correlation integral to define the correlation dimension

$$
v_{\mathrm{m}}=\lim _{\varepsilon \rightarrow 0}\left(\log C_{\mathrm{m}}(\varepsilon) / \log \varepsilon\right)
$$

for small values of $\varepsilon$. If $v_{\mathrm{m}}$ does not increase with $\mathrm{m}$, then the data are consistent with chaotic behavior.

The alternative test is based on the correlation integral described by equations ( 2 , 3). However, it is configured in a manner that radically differs from the way how the BDS statistic is constructed. In order to minimize indecisiveness on what a proper tolerance distance should be, the method suggests the use of a number of tolerance distances for each particular spatial dimension. The tolerance distances are chosen from within a specific range. The alternative statistic is constructed as follows.

The $\log$ of the correlation integral, $\ln \left(\mathrm{C}_{\mathrm{m}}(\varepsilon)\right)$, is plotted against the $\log$ of the proximity parameter, $\ln (\varepsilon)$, for particular spatial dimension $m$. Because numerous tolerance distances $\varepsilon$ are used, then such a plot yields a map of trajectories as illustrated in Figure 1a. Such a representation was used in a conditional variance analysis of exchange rates in Kočenda (1996). These trajectories decrease under different slopes that get steeper as dimension $\mathrm{m}$ becomes larger. At the higher levels of $\mathrm{m}$, the lack of pairs 
lying within the tolerance distance results in increased variance, and the far sections of the trajectories become highly erratic. If a larger number of matched pairs had been included, the variance would asymptotically decrease and the erratic portion of the trajectories would straighten. However, this can be accomplished only by providing an infinite sample of observations. In order to preserve the sections with a constant slope, $\mathrm{C}_{\mathrm{m}}(\varepsilon)$ is constrained accordingly. The map of trajectories then look like one depicted in a Figure $1 b$.

To summarize, an alternative test of the iid hypothesis is developed by calculating the slope of the log of the correlation integral versus the log of the proximity parameter over a broad range of values of the proximity parameter. The slope coefficients will be called $\beta_{\mathrm{m}}$ and can be calculated as

$$
\beta_{\mathrm{m}}=\frac{\sum_{\varepsilon}(\ln (\varepsilon)-\overline{\ln (\varepsilon)})\left(\ln \left(\mathrm{C}_{\mathrm{m}}(\varepsilon)\right)-\overline{\ln \left(\mathrm{C}_{\mathrm{m}}(\varepsilon)\right)}\right)}{\sum_{\varepsilon}(\ln (\varepsilon)-\overline{\ln (\varepsilon)})^{2}}
$$

where $\ln (\varepsilon)$ is the $\log$ of proximity parameter (tolerance distance), $\ln \left(\mathrm{C}_{\mathrm{m}}(\varepsilon)\right)$ is the correlation integral value, and $\mathrm{m}$ is embedding dimension.

As it is evident from their construction, the slope coefficients $\beta_{\mathrm{m}}$ have an interesting feature. A whole range of different tolerance distances $\varepsilon$ is used and slope coefficients are computed over the specified interval. Therefore, slope coefficients $\beta_{\mathrm{m}}$ do not depend on the arbitrary choice of the distance $\varepsilon$. Thus, inadequate choice of $\varepsilon$ is almost eliminated, and the precision of hypothesis testing is highly increased. The same is true for the choice of the dimension $\mathrm{m}$. Again, a whole range of dimensions $\mathrm{m}$ is used 
which gives enough variety to capture more complex dimensional structure without eliminating some unexplored opportunity.

One theoretical feature of the slope coefficients $\beta_{\mathrm{m}}$ is that under the null hypothesis, the data is iid, and these slopes should equal the respective embedding dimension $\mathrm{m}$ at which the statistic is calculated (i.e. $\beta_{\mathrm{m}}=\mathrm{m}$ ). ${ }^{2}$ However, slope coefficient estimates of $\beta_{\mathrm{m}}$ are smaller than respective spatial dimension $\mathrm{m}$, i.e. $\beta_{\mathrm{m}}<\mathrm{m}$. This is because of the following. From (1) and (2) it follows that

$$
\lim _{\mathrm{T} \rightarrow \infty} \mathrm{E}\left(\mathrm{C}_{\mathrm{m}, \mathrm{T}}(\varepsilon)\right)=\mathrm{P}\left(\left|\mathrm{X}_{\mathrm{s}}-\mathrm{X}_{\mathrm{t}}\right|<\varepsilon\right)^{\mathrm{m}}
$$

Taking natural logarithm of both sides yields

$$
\lim _{\mathrm{T} \rightarrow \infty} \ln \mathrm{E}\left(\mathrm{C}_{\mathrm{m}, \mathrm{T}}(\varepsilon)\right)=\mathrm{m} \cdot \ln \mathrm{P}\left(\left|\mathrm{X}_{\mathrm{s}}-\mathrm{X}_{\mathrm{t}}\right|<\varepsilon\right)
$$

Since

$$
P\left(\left|X_{s}-X_{t}\right|<\varepsilon\right)=\int_{-\infty(x-\varepsilon)}^{\infty} \int_{x+\varepsilon)} f(y) f(x) d y d x \cong 2 \varepsilon \int f(x)^{2} d x
$$

is true for small $\varepsilon$. Hence,

$$
\lim _{\varepsilon \rightarrow 0} \frac{P\left(\left|X_{s}-X_{t}\right|<\varepsilon\right)}{\varepsilon}=2 \int f(x)^{2} d x \equiv k
$$

and

$$
\lim _{\varepsilon \rightarrow 0} \frac{\ln P\left(\left|X_{s}-X_{t}\right|<\varepsilon\right)}{\ln \varepsilon}=1
$$

By Jensen's inequality

$$
\mathrm{E} \ln \left(\mathrm{C}_{\mathrm{m}, \mathrm{T}}(\varepsilon)\right) \leq \ln \mathrm{E}\left(\mathrm{C}_{\mathrm{m}, \mathrm{T}}(\varepsilon)\right)
$$

${ }^{2}$ See Hsieh (1991) 
It follows that for large $\mathrm{T}$ and small $\varepsilon$,

$$
\mathrm{E} \ln \left(\mathrm{C}_{\mathrm{m}, \mathrm{T}}(\varepsilon)\right)<\ln \mathrm{E}\left(\mathrm{C}_{\mathrm{m}, \mathrm{T}}(\varepsilon)\right) \cong \mathrm{m} \ln (\mathrm{k})+\mathrm{m} \ln (\varepsilon)
$$

As in the regression

$$
\ln \left(\mathrm{C}_{\mathrm{m}, \mathrm{T}}(\varepsilon)\right)=\alpha+\beta \ln (\varepsilon)+\mathrm{e}
$$

the left hand variable has a negative bias from

$$
\mathrm{m} \ln (\mathrm{k})+\operatorname{mln}(\varepsilon)
$$

Therefore, the smaller $\varepsilon$ is, the smaller the bias, so that the estimated coefficient satisfies

$$
\mathrm{E}[\beta]<\mathrm{m}
$$

This completes the explanation of the nature of the slope coefficients estimates $\left(\beta_{\mathrm{m}}\right)$ being smaller than respective spatial dimension $(\mathrm{m})$.

How do the slope coefficients $\beta_{\mathrm{m}}$ compare to the BDS statistic with reference to their decipherable abilities? The BDS statistic is supposed to stay within a certain confidence interval if the data is white noise. The intuition behind the slope coefficients $\beta_{\mathrm{m}}$ is similar. If the data is identically and independently distributed then the slope coefficients $\beta_{\mathrm{m}}$ must stay within certain confidence intervals as well. Therefore, in order to derive the statistical properties of this test, a Monte Carlo study of the distribution of these slopes under the null hypothesis is performed.

The confidence intervals of the slope coefficients $\beta_{m}$ were calculated using a Monte Carlo technique with 3,000 and 2,000 replications, depending on the length of the white noise time series. In order to obtain the "whitest" white noise observations, a compound random number generator was employed. It is based on the idea of Collings 
(1987) and is constructed from 17 generators described by Fishman and Moore (1982).

This method was chosen for two reasons. First, the method of a compound random numbers generator effectively eliminates repetitiveness in the data which is caused by the limitations of the computer hardware. Secondly, other methods, such as obtaining hypothetically white noise residuals by estimating a generating process (i.e. AR, ARCH, GARCH etc.) may possess some unaccounted for structural form which would bias the critical values in a Monte Carlo simulation.

The simulations generated groups of iid samples containing 500, 1000, and 2500 observations distributed normally with a zero mean and unit variance. Each sample was exposed to the computational procedure of correlation integral allowing for nine embedding spatial dimensions $\mathrm{m}(2-10)$ and 41 tolerance distances $\varepsilon$ ranging over the interval $\langle 0.25 \sigma, 1.0 \sigma\rangle$ by equal increments. Then, slope coefficient estimates of $\beta_{\mathrm{m}}$ were calculated according to the equation (5).

To obtain the most accurate slope coefficient estimates of $\beta_{\mathrm{m}}$ of the constant slope portions of the trajectories, a cut-off point was set. This was done in order to eliminate the erratic portion of the trajectories at the highest spatial dimensions $m$ (7-9). The value of correlation integral was constrained to be 50 by empirical examination of different plots of trajectories resulting from a previous research. ${ }^{3}$ Such a cut-off point does not affect the analysis for lower spatial dimensions $\mathrm{m}$ at all, however, considerably helps to reduce the increasing variance as spatial dimension $\mathrm{m}$ grows larger and tolerance distance $\varepsilon$ becomes smaller. At this moment the value of correlation integral becomes so erratic that only

\footnotetext{
${ }^{3,}$ Cut-off' value for $C_{m}(\varepsilon)$ must be chosen before slope coefficient estimates are computed. $C_{m}(\varepsilon)=50$ resulted from inspecting various trajectories (see Figure 1) resulting from analysis conducted on different time series.
} 
notable increases in a number of replications could cure the roughness, and hence, lessen the variance.

Finally, quantiles for slope coefficient estimates $\beta_{\mathrm{m}}$ at different dimensional levels were tabulated. ${ }^{4}$ Table 1 presents the quantiles to allow a hypothesis testing at levels of 1 , 2, 5, and 10 percents for a time series of 500 observations. Tables 2 and 3 present the quantiles for a time series of the length 1000 and 2500 observations, respectively. Let $\mathrm{L}_{\alpha}$ and $U_{\alpha}$ be lower and upper bounds of the $(100-\alpha)$ percentage confidence interval of the distribution. If $\left(\mathrm{x}<\mathrm{L}_{\alpha}\right) \vee\left(\mathrm{x}>\mathrm{U}_{\alpha}\right)$, then null hypothesis of iid can be rejected at the $\alpha$ percent confidence level.

\section{Power Tests and Empirical Comparison}

\subsection{Power Tests}

The power of the method is tested against some nonlinear data resulting from processes described below. Their choice is based on their common use, and the fact that they do not contain any linear structure. This eliminates the problem of removing linear structure by taking residuals of a fitted linear model.

The first model used is the nonlinear moving average (NLMA) in the following form:

$$
\mathrm{x}_{\mathrm{t}}=5 \varepsilon_{\mathrm{t}-1} \varepsilon_{\mathrm{t}-2}+\varepsilon_{\mathrm{t}}
$$

\footnotetext{
${ }^{4}$ The 'slope test' does not simultaneously test that $\beta_{1}=1$ and $\beta_{2}=2 \ldots$ and $\beta_{\mathrm{m}}=\mathrm{m}$ and so it too has a problem when some of the slopes are in the right range, and some are not.
} 
The $\varepsilon_{\mathrm{t}}$ terms are iid normal. The second model is the ARCH model of Engle (1982) that can be represented in the following form:

$$
\begin{aligned}
& \mathrm{x}_{\mathrm{t}} \sim \mathrm{N}\left(0, \mathrm{~h}_{\mathrm{t}}\right) \\
& \mathrm{h}_{\mathrm{t}}=\alpha_{0}+\sum_{\mathrm{i}=1}^{\mathrm{q}} \alpha_{\mathrm{i}} \mathrm{x}_{\mathrm{t}-\mathrm{i}}^{2}
\end{aligned}
$$

where in this case $\mathrm{q}=1, \alpha_{0}=1$, and $\alpha_{1}=0.5$.

Table 4 shows the power of the test against specific models for lengths of 500 , 1000, and 2500 observations. The numbers represent the frequency of rejection at the 5\% confidence level. Derivation of critical values is described in the previous section. Power of the test against specified models is comparable with the power of the BDS statistic shown in Hsieh and LeBaron (1988) and Brock, Dechert, Scheinkman, and LeBaron (1996). However, due to the characteristics of the correlation integral, the power naturally declines at the highest levels of embedding dimension.

Series that exhibit zero autocorrelation structure, as the above models do, are rarely found in practical application. The suggested method is, therefore, meant as a residual diagnostic for empirical analysis. The following examples of empirical comparisons suggest the usefulness and added value of the proposed testing method.

\subsection{Empirical Comparison}

High frequency financial data reflect fully a stylized fact of changing variance over time. Numerous financial time series were studied and found to contain linear as well as non-linear dependencies. An appropriate model that would account for conditional heteroskedasticity in such time series should be able to remove possible 
nonlinear patterns in the data. Standardized (fitted) or corrected residuals from such a model are an ideal material to be confronted with the BDS test as well as with the suggested alternative method because if the null model is correctly specified, then those residuals should be independent. In other words, they should not contain any other useful forecastable structure. Thus, the test can be used not only as a test for nonlinearity but as a correct specification test as well.

Four empirical studies were chosen to be replicated in order to yield comparisons between the two tests. Notation throughout this section is kept for clarity as in original studies. Results show that suggested alternative is able to detect remaining non-linear dependencies in standardized (fitted) residuals where the BDS test does not.

\subsubsection{Analysis of weekly exchange rates}

Kugler and Lenz (1990) analyzed non-linear dependence of exchange rate changes for four currencies against the US dollar. They used weekly end of period data of Deutsche Mark (DMUS), Swiss Franc (SFUS), French Franc (FFUS), and Japanese Yen (YNUS). The sample period is $1979-1989$ and has $\mathrm{T}=575$ observations for the rate of change of the $\log$ exchange rate $x_{t}=\Delta \log S_{t}$. The LM test performed on the rate of changes clearly indicates presence of autoregressive conditional heteroskedasticity, and the BDS test decisively rejects the null of iid. The data was corrected to account for the $\mathrm{ARCH}$ process by transformation into the $\mathrm{ARCH}$ corrected rate of changes in a form

$$
\Delta \log \mathrm{S}_{\mathrm{t}}^{\mathrm{h}}=\frac{\Delta \log \mathrm{S}_{\mathrm{t}}}{\left(\hat{\alpha}_{0}+\sum_{\tau=1}^{6} \hat{\alpha}_{\tau} \Delta \log \mathrm{S}_{\mathrm{t}-\tau}^{2}\right)^{0.5}}
$$


where $\alpha$-coefficients were obtained by OLS regression of $\left(\Delta \log \mathrm{S}_{\mathrm{t}}\right)^{2}$ on constant and six lagged variables. Such ARCH corrected rate of changes were subjected to the BDS test using spatial dimensions $\mathrm{N}=2,3,4$, and 5 , and tolerance distances $\varepsilon=0.5,0.75,1.0$, and 1.5 of the standard deviation of the sample. Kugler and Lenz (1990) found that the described correction successfully removed nonlinearity from the Swiss Franc and Deutsche Mark. However, the BDS test did not allow rejection of the null hypothesis for the French Franc (specifically at levels of $\mathrm{N}=4$ and 5) and Japanese Yen (specifically at levels of $\mathrm{N}=3,4$, and 5).

I have replicated the original study with the same results and applied the corrected rates to the alternative test. The results are presented in Table 5. As in the original study, the null hypothesis is rejected for the French Franc and Japanese Yen. Contrary to the original analysis, the alternative test finds remaining non-linear dependency in the residuals of the Deutsche Mark. Swiss Franc is the only currency where the null of iid cannot be rejected. The alternative test confirmed presence of non-linearity in the corrected residuals of the French Franc and Japanese Yen, and detected remaining dependency in presumably independent Deutsche Mark.

\subsubsection{Analysis of daily exchange rates}

Brock, Hsieh, and LeBaron (1993), p. 130, analyzed daily closing bid prices of the five major currencies in U.S. Dollars: Swiss Franc (SF), Canadian Dollar (CD), Deutsche Mark (DM), British Pound (BP), and Japanese Yen (JY) during the period from January 
2, 1974 to December $30,1983 .{ }^{5}$ The length of the time series is 2,510 observations. The analysis was based on Hsieh (1989).

As in the original study, the rates of change are calculated by taking the first logarithmic differences between successive trading days. The data were prefiltered by an autoregressive process with daily dummies to remove linear dependency. In order to capture variance-nonlinearity a GARCH model of exchange rates was estimated. The specification of the model resulted into the following mean equation:

$$
r_{t}=\beta_{0}+\sum_{i=1}^{j} \beta_{i} r_{t-i}+\beta_{M} D_{M, t}+\beta_{T} D_{T, t}+\beta_{w} D_{w, t}+\beta_{R} D_{R, t}+\beta_{H} D_{H}+u_{t}
$$

where, $\mathrm{u}_{\mathrm{t}} \mid \Omega_{\mathrm{t}-1} \sim \mathrm{D}\left(0, \mathrm{~h}_{\mathrm{t}}\right)$, and variance equation

$$
\mathrm{h}_{\mathrm{t}}=\phi_{0}+\psi \mathrm{u}_{\mathrm{t}-1}^{2}+\phi \mathrm{h}_{\mathrm{t}-1}+\phi_{\mathrm{M}} \mathrm{D}_{\mathrm{M}, \mathrm{t}}+\phi_{\mathrm{T}} \mathrm{D}_{\mathrm{T}, \mathrm{t}}+\phi_{\mathrm{W}} \mathrm{D}_{\mathrm{w}, \mathrm{t}}+\phi_{\mathrm{R}} \mathrm{D}_{\mathrm{R}, \mathrm{t}}+\phi_{\mathrm{H}} \mathrm{D}_{\mathrm{H}}
$$

where $r_{t}$ is a rate of change of the nominal exchange rate at time t, and $D_{\mathrm{M}, t}, \mathrm{D}_{\mathrm{T}, \mathrm{t}}, \mathrm{D}_{\mathrm{W}, \mathrm{t}}$, and $\mathrm{D}_{\mathrm{R}, \mathrm{t}}$, are dummy variables for Monday, Tuesday, Wednesday, and Thursday, and $\mathrm{D}_{\mathrm{H}}$ is the number of holidays between two successive trading days excluding week-ends. Daily dummies were included to capture the daily effects of fluctuations that are known to materialize in correlation at financial markets and thus might affect the analysis. The order of an autoregressive process is determined to be $\mathrm{j}=6,5,6$, and 0 respectively for $\mathrm{SF}, \mathrm{CD}, \mathrm{DM}$, and $\mathrm{BP}$.

The BDS test was performed on the raw data as well as on the prefiltered data. The results in both cases do not differ. The data are not white noise. After estimation, the overall fit of the model is accessed by performing diagnostic tests on standardized residuals $z_{t}=u_{t} / h_{t}^{\frac{1}{2}}$ where $u_{t}$ is the residual of the mean equation (19), and $h_{t}$ is the

\footnotetext{
${ }^{5}$ Japanese yen was dropped from the replication because of a data inconsistency.
} 
estimated conditional variance from equation (20). The BDS test finds no evidence of nonlinearity in standardized residuals of SF, some nonlinearity (at dimensions 8, 9, and 10) for the DM, and strong nonlinearity for CD and BP.

Replicated findings are in accordance with the above stated findings of Brock, Hsieh, and LeBaron (1993), pp. 140 and $155 .^{6}$ Then, the standardized residuals are subjected to the alternative test. The slope coefficients derived from the test on standardized residuals are presented in the Table 6. DM and BP show presence of nonlinearity at the $1 \%$ significance level no matter what embedding dimension is considered. CD and SF show some presence of nonlinearity at various significance levels depending on spatial dimension $\mathrm{m}$. The alternative test confirmed the presence of nonlinearity in $\mathrm{DM}, \mathrm{CD}$, and $\mathrm{BP}$ and, contrary to the original study, detected remaining nonlinearity in supposedly independent residuals of SF.

\subsubsection{Analysis of weekly exchange rates}

Kugler and Lenz (1993) analyzed non-linear dependence of exchange rate changes for ten currencies against the US dollar. They used weekly end of period data of Australian dollar (ADUS), Canadian dollar (CDUS), Belgian Franc (BFUS), French Franc (FFUS), Deutsche Mark (DMUS), Dutch Guilder (HFUS), Italian Lira (LTUS), Spanish Peseta (PTUS), Swiss Franc (SFUS), and Japanese Yen (YNUS). The sample period is $1979-1989$ and has $\mathrm{T}=575$ observations for the rate of change of the $\log$ exchange rate $x_{t}=\Delta \log S_{t}$. The LM test performed on the rate of changes clearly

\footnotetext{
${ }^{6}$ There is an descriptive error in Brock, Hsieh, and LeBaron (1993) on this subject. At p. 140 it is claimed that BDS test finds no evidence of nonlinearity in CD. However, at p. 155 the Table shows that statistics
} 
indicates the presence of autoregressive conditional heteroskedasticity, and the BDS test decisively rejects the null of iid. In order to check whether the detected dependence can be solely attributed to an ARCH process, they estimated the following GARCH-M model

$$
\begin{aligned}
& \Delta \log \mathrm{S}_{\mathrm{t}}=\beta_{0}+\sum_{\tau=1}^{3} \beta_{\tau}+\Delta \log \mathrm{S}_{\mathrm{t}-\tau}+\beta_{4} \sqrt{\mathrm{h}_{\mathrm{t}}}+\eta_{\mathrm{t}} \\
& \mathrm{h}_{\mathrm{t}}=\alpha_{0}+\alpha_{1} \eta_{\mathrm{t}-1}^{2}+\alpha_{2} \mathrm{~h}_{\mathrm{t}-1} \quad \eta_{\mathrm{t}}=\varepsilon_{\mathrm{t}} \sqrt{\mathrm{h}_{\mathrm{t}}}
\end{aligned}
$$

In equation (21) linear dependencies of the AR type are allowed for, as the estimated pure GARCH-M model showed signs of residual autocorrelation for some currencies. For all currencies the GARCH coefficients $\hat{\alpha}_{1}$ and $\hat{\alpha}_{2}$ are highly significant from zero. Thus ARCH effects are important for all currencies. Finally, the fitted residuals $\hat{\varepsilon}_{t}=\eta_{t} / \sqrt{h_{t}}$ were subjected to the BDS test (tolerance distance of one standard deviation and embedding dimensions $\mathrm{N}=2,3,4$, and 5 were used). Results revealed that there was no indication of dependence in the fitted residuals of any currency.

I have replicated the study with the same results. Then, the fitted residuals $\hat{\varepsilon}_{\mathrm{t}}$ were subjected to the alternative test. The results, that are presented in Table 7, confirmed the original findings for five out of ten currencies being independent (CDUS, FBUS, FFUS, HFUS, and SFUS). However, contrary to the original analysis, the alternative method was able to detect remaining non-linear dependencies in fitted residuals for the rest of supposedly independent currencies (ADUS, DMUS, LTUS, PTUS, and YNUS).

\subsubsection{Analysis of daily stock market index}

for CD are significant at $1 \%$ level, thus, supporting the evidence of nonlinearity in standardized residuals of this currency. 
Olmeda and Perez (1995) explored the existence of non-linear dynamics and chaos in the Spanish stock market. Their database is composed of 1256 observations (from January 2, 1989 to January 31, 1994) of the General Index of Madrid's Stock Market, not corrected for dividends or splits. Using the BDS test they found that the returns series shows significant linear and non-linear dependence. They estimated a GARCH $(1,1)$ model for AR(1) residuals in a form

$$
x_{t}=\sigma_{t} u_{t}, \sigma_{t}^{2}=\alpha_{0}+\alpha_{1} x_{t-1}^{2}+\beta \sigma_{t-1}^{2}, u_{t} \sim N(0,1)
$$

and formed the standardized residuals $s_{t}=e_{t} / \sigma_{t}$ of this model. They found that the BDS statistic values were still significant at 5\% level, showing that the GARCH $(1,1)$ model could not account for all the nonlinearity.

The estimation was replicated with the equal results and then the standardized residuals were subjected to the alternative test. The results are presented in Table 8 . It is evident that the null hypothesis of iid can be decisively rejected at $1 \%$ level. The test thus even strongly confirmed original findings.

\section{Conclusion}

This paper has presented a new method of testing for iid. The method originates in a chaos theory and is based on the concept of the correlation integral. The test is suggested as an alternative to a widely used nonparametric BDS test. The BDS test requires two parameters, proximity parameter $\varepsilon$ and embedding dimension $\mathrm{m}$, to be chosen arbitrarily ex ante. Only a limited statistical theory exists to determine the right choice of these parameters for particular data set. Presented new method eliminates, to a large extent, indecisiveness in the choice of these parameters by integration over the 
correlation integral. An alternative statistic is developed by calculating the slope of the log of the correlation integral versus the log of the proximity parameter over a broad range of values of the proximity parameter for different embedding dimensions. The Monte Carlo simulation is used to tabulate critical values of the slope coefficients $\beta_{\mathrm{m}}$ at different significance levels.

The power of the new method is tested against some nonlinear artificial data. A comparative analysis of four empirical studies is executed in order to evaluate its performance. The presented test is applied on standardized or corrected residuals from different models and is able to find nonlinear dependencies in cases where the BDS test does not find them. Thus, the alternative test becomes more critical to the question whether the data is true white noise or whether some nonlinear pattern hides undetected within a time series.

The importance of having a good test for detecting nonlinearity in a time series and especially in the residuals from the null model is ever more important with the increasing number of sophisticated quantitative methods being implemented into finance and macroeconomics. The proposed methodology with increased sensitivity is believed to be helpful in future research and its applications. 

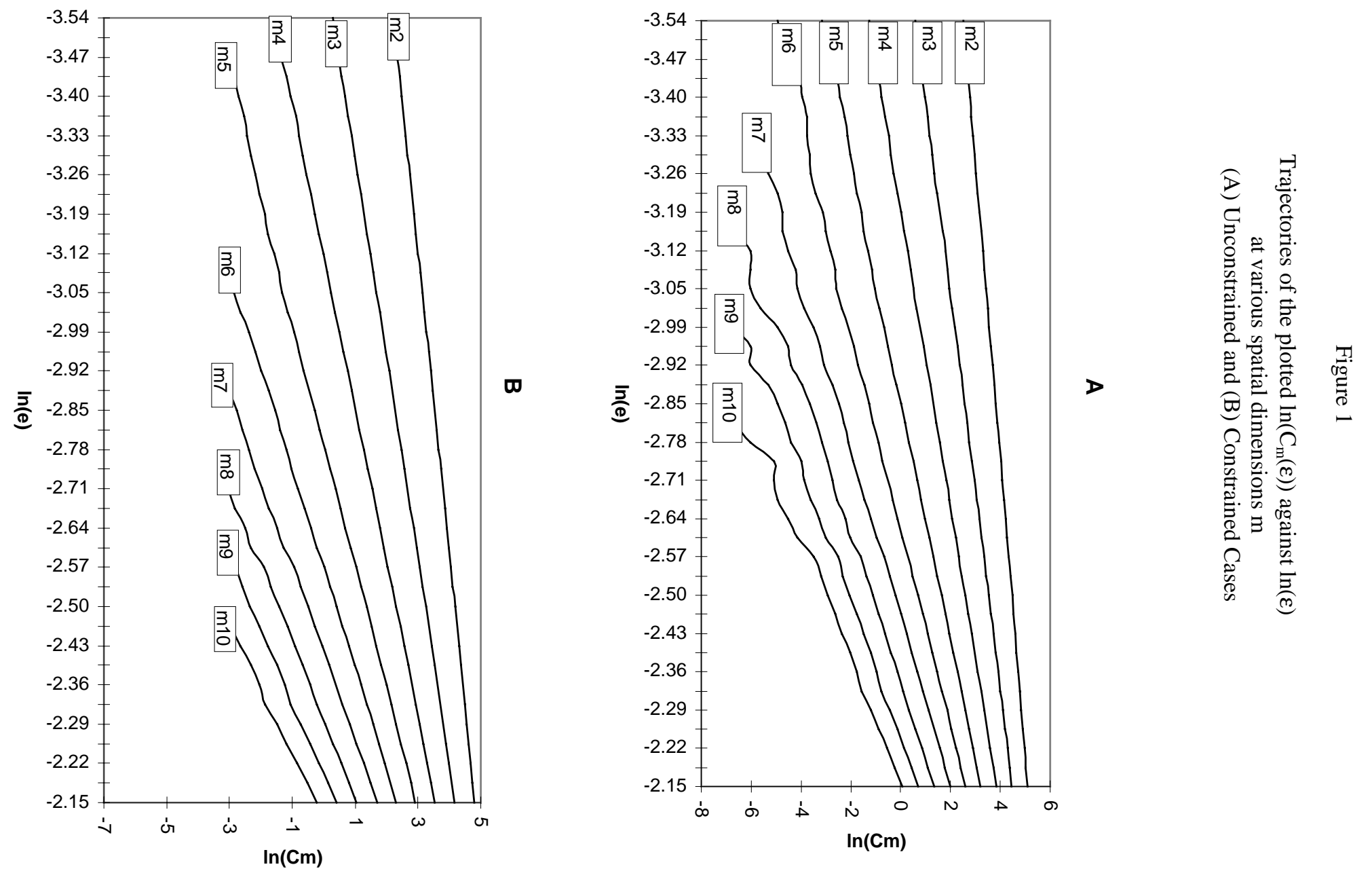


\section{References}

Anderson, P. W., Arrow, K. J., and Pines, D., editors, 1988, The Economy as an Evolving Complex System, Santa Fe Institute Studies in the Sciences of Complexity, v. 5 (Addison-Wesley Publishing Company)

Bollerslev, T., 1986, Generalized Autoregressive Conditional Heteroskedasticity, Journal of Econometrics, 31, 307-327.

Brock, W., 1988, Nonlinearity and Complex Dynamics in Economics and Finance in Anderson, P. W., Arrow, K. J., and Pines, D., editors, 1988, The Economy as an Evolving Complex System, Santa Fe Institute Studies in the Sciences of Complexity, v. 5 (Addison-Wesley Publishing Company)

Brock, W., and Dechert, W., 1988, A General Class of Specification Tests: The Scalar Case, in Business and Economics Statistics Section of the Proceeding of the American Statistical Society, pp. 70-79.

Brock, W., Dechert, W., and Scheinkman, J., 1987, A Test for Independence Based on the Correlation Dimension, University of Wisconsin at Madison, Department of Economics Working Paper.

Brock, W., Dechert, W., Scheinkman, J., and LeBaron, B., 1996, A Test for Independence Based on the Correlation Dimension, forthcoming in Econometric Reviews

Brock, W. A., Hsieh, D. A., and LeBaron, B., 1993, Nonlinear Dynamics, Chaos, and Instability: Statistical Theory and Economic Evidence, The MIT Press, Cambridge, Massachusetts

Collings, B. J., 1987, Compound Random Number Generators, Journal of the American Statistical Association, 82, Theory and Methods, 525-527

Dechert, W. D., 1994, The Correlation Integral and the Independence of Gaussian and Related Processes, SSRI Working Paper 9412, University of Wisconsin-Madison

DeLima, P., 1992, A Test for IID Based upon the BDS Statistic, Department of Economics, Johns Hopkins University

Engle, R. F., 1982, Autoregressive Conditional Heteroskedasticity with Estimates of the Variance of United Kingdom Inflation, Econometrica, 50, 987-1007.

Fishman, G. S., and Moore, L. R., 1982, A Statistical Evaluation of Multiplicative Congruential Random Number Generators with Modulus $2^{31}-1$, Journal of the American Statistical Association, 77, Theory and Methods, 129-136 
Grassberger, P., and Procaccia, I., 1983, Measuring the Strangeness of Strange Attractors, Physica 9D, 189-208.

Hsieh, D. A., 1989, Testing for Nonlinear Dependence in Daily Foreign Exchange Rates, Journal of Business 62, 339-368.

Hsieh, D. A., 1991, Chaos and Nonlinear Dynamics: Application to Financial Markets, Journal of Finance 46, 1839-1877.

Hsieh, D. A., and LeBaron, B., 1988, Finite Sample Properties of the BDS Statistic, University of Chicago and University of Wisconsin-Madison, in Brock, W. A., Hsieh, D. A., and LeBaron, B., Nonlinear Dynamics, Chaos, and Instability: Statistical Theory and Economic Evidence, The MIT Press, Cambridge, Massachusetts, 1993

Kočenda, E., 1997, Volatility of a Seemingly Fixed Exchange Rate, forthcoming in Eastern European Economics

Kugler, P., and Lenz, C., 1990, Sind Wechselkursfluktuationen zufullig oder chaotisch? (Are Exchange Rate Fluctuations Random or Chaotic?), Schweizerische Zeitschrift für Volkswirtschaft und Statistik, 126(2), 113-128

Kugler, P., and Lenz, C., 1993, Chaos, ARCH, and the Foreign Exchange Market: Empirical Results from Weekly Data, Rivista Internazionale di Scienze Economiche e Commerciali, 40(2), 127-140

Olmeda, I., and Perez, J., 1995, Non-linear Dynamics and Chaos in the Spanish Stock Market, Investigaciones Economicas, 19(2), 217-248 